\title{
Gonad-infecting philometrids (Nematoda: Philometridae) including four new species from marine fishes off the eastern coast of India
}

\author{
František Moravec $^{1}$ and Jayaraman Manoharan ${ }^{2}$
}

${ }^{1}$ Institute of Parasitology, Biology Centre of the Academy of Sciences of the Czech Republic, České Budějovice, Czech Republic;

${ }^{2}$ Faculty of Marine Sciences, Annamalai University, Tamil Nadu, India

\begin{abstract}
Based on light and scanning electron microscopical studies, the following five gonad-infecting species of the Philometridae (Nematoda: Dracunculoidea) are described from marine perciform fishes off the eastern coast of India (Bay of Bengal): Philometra sphyraenae sp. n. (males and females) from the pickhandle barracuda Sphyraena jello Cuvier (Sphyraenidae), Philometra gerrei sp. n. (males and females) from the whipfin silver-biddy Gerres filamentosus Cuvier (Gerreidae), Philometra otolithi sp. n. (single female) from the tigertooth croaker Otolithes ruber (Bloch et Schneider) (Sciaenidae), Philometra sp. (females) from the Belanger's croaker Johnius belangerii (Cuvier) (Sciaenidae), and Philometroides eleutheronemae sp. n. (females) from the fourfinger threadfin Eleutheronema tetradactylum (Shaw) (Polynemidae). All new species are distinguished from their congeners parasitizing gonads of marine fishes by morphological (mainly the gubernaculum structure in males and the shape and structure of the cephalic and caudal ends and of the oesophagus in females) and biometrical features. Philometra rajani Mukherjee, 1963 is considered a species inquirenda.
\end{abstract}

Keywords: Dracunculoidea, Bay of Bengal, marine fishes, fish parasites, hosts, parasitic nematode, taxonomy

As reported by Moravec et al. (2011a), gonad-infecting species of philometrid nematodes (Philometridae) are widely distributed in marine fishes of the Atlantic, Indian and Pacific Oceans, sometimes also occurring in brackish-water environments. These parasites may be severely pathogenic in fish ovaries and can affect reproduction (see Moravec and de Buron 2013).

In the Indian Ocean region, a total of seven nominal, gonad-infecting species of philometrid nematodes, all belonging to Philometra Costa, 1845, have been reported from a variety of marine fishes belonging to different families: P. cephalus Ramachandran, 1975, P. globiceps (Rudolphi, 1819), P. lateolabracis (Yamaguti, 1935), P. neolateolabracis Rajyalakshmi, Hanumantha Rao et Shyamasundari, 1985, P. pellucida (Jägerskiöld, 1893), $P$. rajani Mukherjee, 1963 and $P$. terapontis Moravec, Gopalakrishnan, Rajkumar, Saravanakumar et Kaliyamoorthy, 2011. In addition, several gonad-infecting philometrids from this same region have been reported only as Philometra sp. (Mukherjee 1963, Rasheed 1963, 1965, Parukhin 1976, 1989, Rajyalakshmi et al. 1985, Petter and Sey 1997, Kardousha 1999, Hesp et al. 2002, Moravec 2006, Mohamed et al. 2010, Moravec et al. 2011a). However, P. lateolabracis and $P$. pellucida reported from fishes in the Indian Ocean were evident misidentifications
(Moravec 2006, 2008, Quiazon et al. 2008a), whereas $P$. neolateolabracis and P. rajani were designated as species inquirendae (see Moravec et al. 2011a, this study). Also the record of $P$. globiceps from a carangid fish off Kuwait by Petter and Sey (1997) was probably a misidentification (Moravec et al. 2012b).

\section{MATERIALS AND METHODS}

Fish were caught by trawl nets by local fishermen in the Bay of Bengal and were obtained in the landing centres Cuddalore $\left(11^{\circ} 42^{\prime} \mathrm{N}, 74^{\circ} 46^{\prime} \mathrm{E}\right)$, Parangipettai $\left(11^{\circ} 29^{\prime} \mathrm{N}, 7^{\circ} 46^{\prime} \mathrm{E}\right)$ and Pazhayar $\left(11^{\circ} 21^{\prime} \mathrm{N}, 79^{\circ} 50^{\prime} \mathrm{E}\right)$ on the eastern coast of India (Fig. 1). The nematodes collected from fish gonads were washed in physiological saline and were then fixed and preserved in $4 \%$ formaldehyde solution. Philometrid males were dissected out from formalin-fixed fish ovaries. For light microscopy examination, the nematodes were cleared with glycerine. Drawings were made with the aid of a Zeiss drawing attachment. Specimens used for scanning electron microscopy (SEM) were postfixed in $1 \%$ osmium tetroxide (in phosphate buffer), dehydrated through a graded acetone series, critical-point-dried and sputter-coated with gold; they were examined using a JEOL JSM-7401F scanning electron microscope at an accelerating voltage of $4 \mathrm{kV}$ (GB low mode). All measurements are in micrometres unless otherwise indicated. The fish nomenclature adopted follows FishBase (Froese and Pauly 2012). 


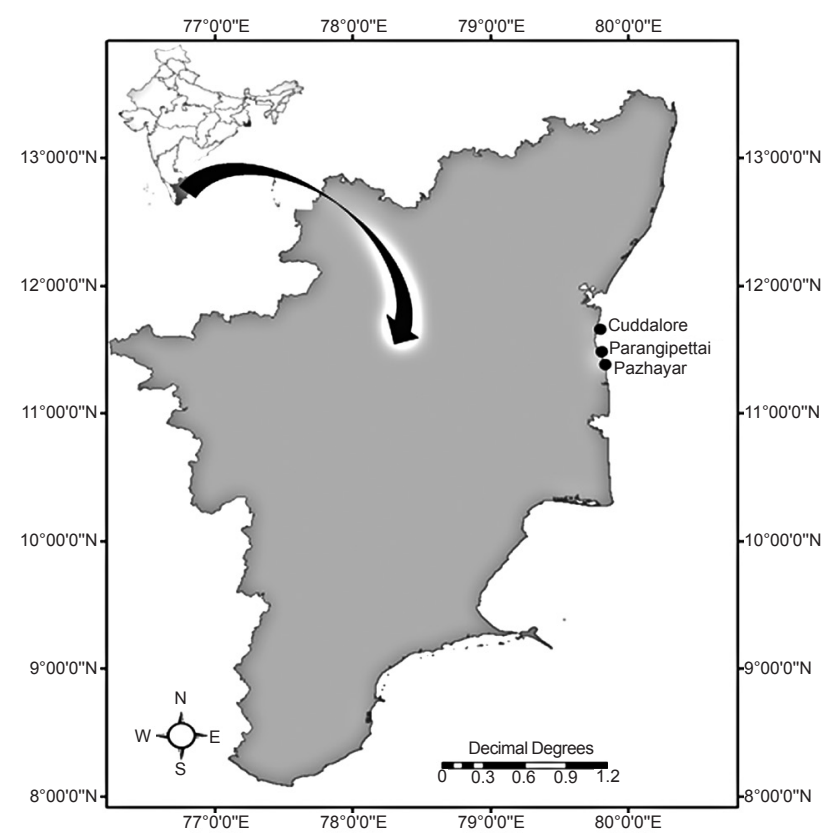

Fig. 1. Map of the sampling area.

\section{RESULTS AND DISCUSSION}

Family Philometridae Baylis et Daubney, 1926

Philometra sphyraenae sp. n.

Figs. 2-4

Male (ten specimens; measurements of holotype in parentheses): Body filiform, whitish, 2.07-2.76 (2.38) $\mathrm{mm}$ long, maximum width at middle 57-66 (60); anterior part of body markedly narrower than middle and posterior parts, with slightly outlined narrower neck portion (Fig. 2I); body width at this narrower neck part 27-33 (27). Maximum width/body length 1:36-42 (1:40); width of cephalic end 30-33 (30), that of posterior end 33-36 (33). Cuticle smooth. Cephalic end rounded.

Oral aperture small, triangular, surrounded by 14 small cephalic papillae arranged in two circles: external circle formed by four submedian pairs of papillae (each pair consisting of one circular and one narrower, more elongate papilla); internal circle by four submedian and two lateral papillae. Small lateral amphids just posterior to lateral papillae of internal circle (Figs. 2E, 3A,B). Oesophagus 396-528 (420) long, forming 17-22\% $(18 \%)$ of body length, with slight inflation at anterior end; posterior part of muscular oesophagus overlapped by well developed oesophageal gland with large cell nucleus in middle (Fig. 2I). Oesophageal nucleus and nerve ring 306-384 (312) and 141-174 (141), respectively, from anterior extremity. Excretory pore 159-219 (180) from anterior end.

Testis not reaching anteriorly to level of nerve ring. Posterior end of body blunt, with broad, two-lobed, kidney-shaped, lateral mounds; dorsal ends of mounds far from each other (Figs. 2L, 4A-D). One pair of preanal, two pairs of adanal and one pair of postanal very flat, hardly visible caudal papillae close to each other located near cloacal aperture on mounds (Figs. 2L, 4C-E); additional pair of small postanal papillae present on dorsal ends of mounds; pair of larger ventral papillae situated posterior to cloacal aperture, at level of middle part of lateral mounds (Figs. 2L, 4A-E). Minute phasmids posterior to dorsal ends of mounds (Figs. 2L, 4C).

Spicules slender, needle-like, equally or slightly subequally long, with somewhat expanded proximal and sharply pointed distal tips (Figs. 2J,K, 4A,C,E); length of spicules 120-132 (126), comprising 4.7-6.0\% (5.3\%) of body length. Gubernaculum narrow, 66-75 (75) long, with anterior portion somewhat dorsally bent; length of anterior bent part 27-33 (33), comprising 40-44\% (44\%) of entire gubernaculum length; posterior end of gubernaculum with dorsal protuberance, smooth, rounded (Figs. 2J,K,M, 4F). Length ratio of gubernaculum and spicules $1: 1.68-1.87(1: 1.68)$. Spicules and gubernaculum well sclerotized, yellowish, anterior part of gubernaculum colourless.

Gravid female (two larvigerous specimens, measurements of allotype in parentheses): Body of fixed specimens whitish, with distinct dark-coloured intestine visible through cuticle, with rounded ends. Posterior part of body narrower than anterior part; maximum width in region posterior to oesophagus. Cuticle smooth. Body length 170-450 (450) mm, maximum width 1.06-1.36 (1.36) $\mathrm{mm}$, maximum width/body length ratio $1: 160-331$ (1:331). Width of cephalic end 245-299 (299). Cephalic papillae small, almost indistinct when viewed laterally (Fig. 2A,B).

Oral aperture oval to somewhat triangular, surrounded by four pairs of submedian cephalic papillae of external circle and six single papillae (two lateral and four submedian) of internal circle (Figs. 2C, 3A,C-F). Amphids indistinct. Oesophagus including slightly outlined anterior bulbous inflation 1.10-1.73 (1.73) mm long, representing $0.4-0.6 \%(0.4 \%)$ of body length; bulb almost indistinct, 109-190 (190) long and 109-150 (150) wide (Fig. 2A,B); maximum width of oesophagus including gland 95-231 (231). Oesophageal gland relatively narrow, opening into oesophagus just posterior to nerve ring, with large cell nucleus in middle (Fig. 2A). Nerve ring and oesophageal nucleus 218-517 (517) and 585-1 115 (1115), respectively, from anterior extremity. Small ventriculus 41-45 (45) long and 82-126 (126) wide. Oesophagus opening into intestine through distinct valve (Fig. 2A). Intestine narrow at anterior end; its posterior end narrow, attached by ligament ventrally to body wall near caudal end; ligament 762-1224 (762) long (Fig. 2F).

Vulva and anus atrophied. Ovaries relatively short, reflected, situated near body ends (Fig. 2A,F). Uterus occupying most space of body, filled with numerous lar- 

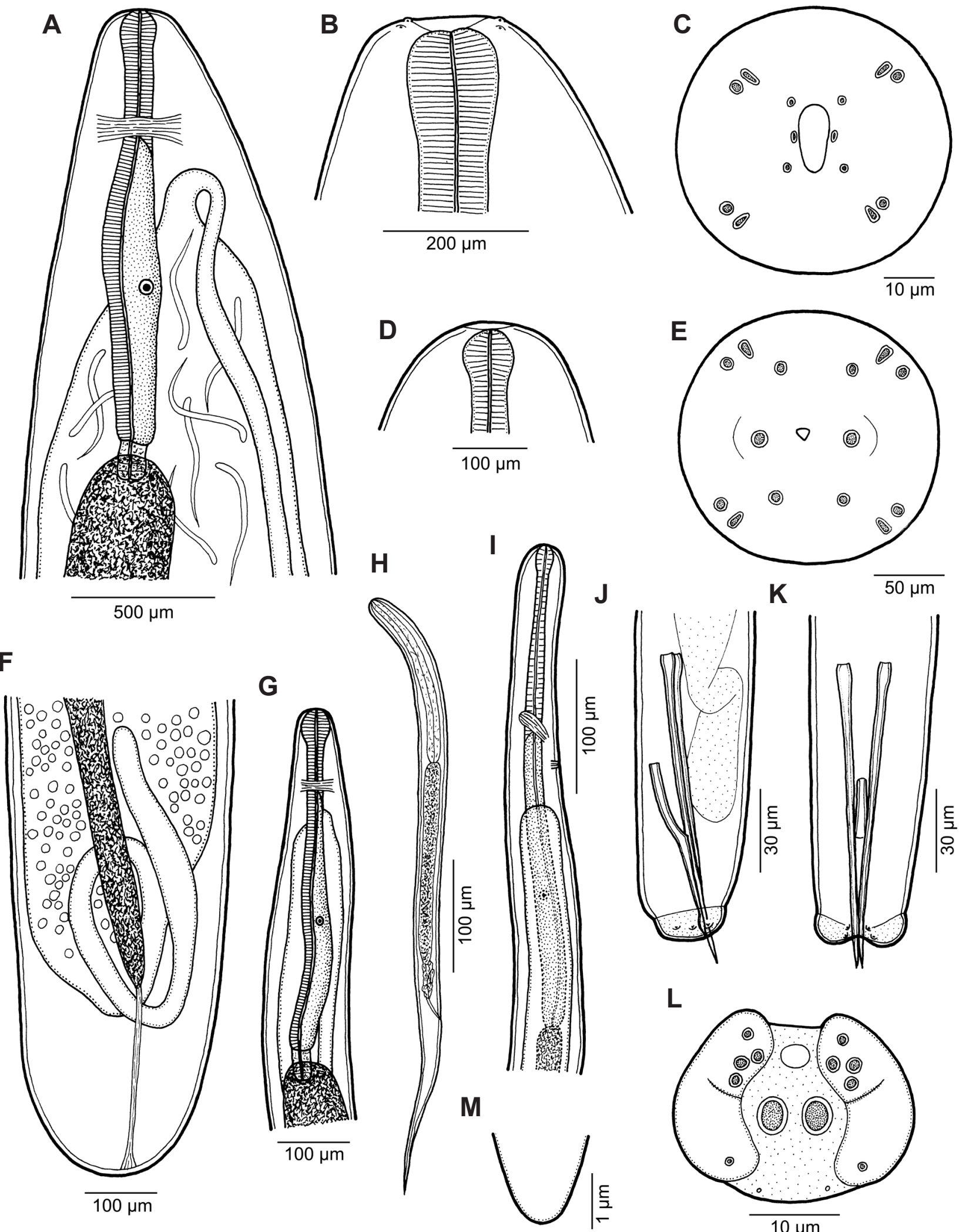

Fig. 2. Philometra sphyraenae sp. n. A - anterior end of gravid female, lateral view; $\mathbf{B}, \mathbf{C}$ - cephalic end of largest gravid female, lateral and apical views; D - cephalic end of subgravid female, lateral view; $\mathbf{E}$ - cephalic end of male, apical view; $\mathbf{F}$ - posterior end of largest gravid female, lateral view; $\mathbf{G}$ - anterior end of smallest female, lateral view; $\mathbf{H}$ - larva from uterus, lateral view; $\mathbf{I}$ - anterior end of male, lateral view; $\mathbf{J}, \mathbf{K}$ - posterior end of male, lateral and ventral views; $\mathbf{L}$ - caudal end of male, apical view (schematized); $\mathbf{M}$ - distal end of gubernaculum, dorsal view. 

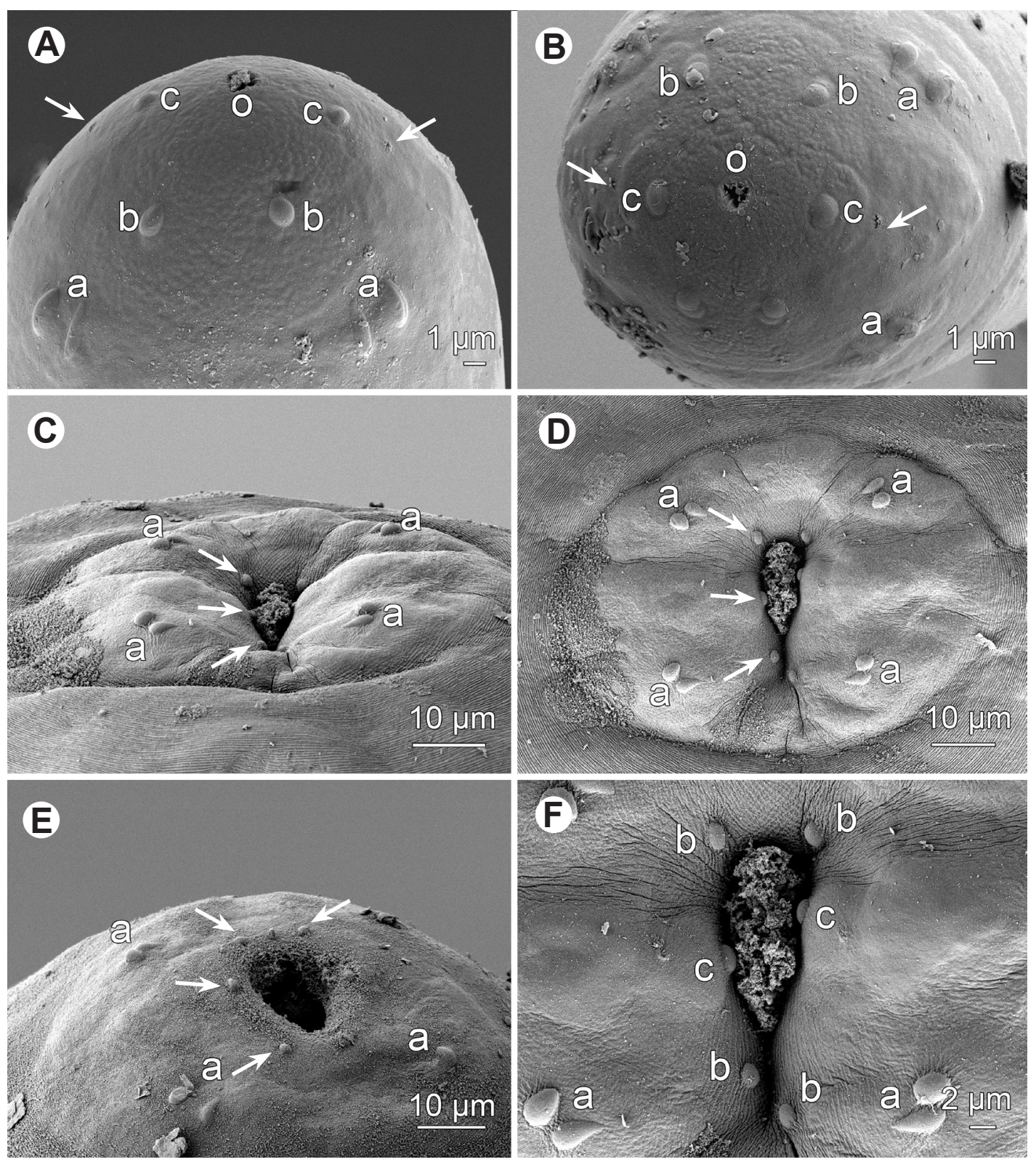

Fig. 3. Philometra sphyraenae sp. n., scanning electron micrographs. A, B - cephalic end of male, dorsoventral and apical views (arrows indicate amphids); C, D - cephalic end of subgravid female, dorsoventral and apical views (arrows indicate papillae of internal circle); $\mathbf{E}$ - cephalic end of subgravid female (another specimen), subapical view (arrows indicate papillae of internal circle); F - region of oral aperture of female, apical view. Abbreviations: a - submedian pair of external cephalic papillae; $\mathrm{b}$ - submedian cephalic papilla of internal circle; $\mathrm{c}$ - lateral cephalic papilla of internal circle; $\mathrm{o}$ - oral aperture.

vae with markedly long, slender tail (Fig. 2H); larvae $(\mathrm{n}=5)$ in allotype 544-585 long and 15-18 wide; length of oesophagus 150-174, of tail 180-222, comprising 26-31\% and 32-39\%, respectively, of entire body length of larva. Posterior end of female rounded, 367-544 (544) wide, without any caudal projections (Fig. 2F).

Subgravid female (four ovigerous specimens): Body length 32-107 mm, maximum width 340-734; maximum width/length ratio $1: 55-162$. Width of anterior end 150-258, of posterior end 163-272. Entire oesophagus 585-1 102 long, representing $1.5-1.8 \%$ of body length, and
82-95 wide. Anterior oesophageal bulb $68-75 \times 68-82$, ventriculus $27-45 \times 68-69$. Nerve ring and oesophageal nucleus $163-218$ and 381-639, respectively, from anterior extremity. Intestinal ligament 748-1387 long. Vulva and vagina absent. Uterus filled with many eggs.

Nongravid female (two specimens): Body length 5.21-8.66 mm, maximum width 150-190; maximum width/length ratio $1: 35-46$. Width of anterior end 54-82, of posterior end 82. Entire oesophagus 530-585 long, representing $6.8-10.2 \%$ of body length, and $41-54$ wide. Anterior oesophageal bulb 41-54 × 41-68. Nerve ring 

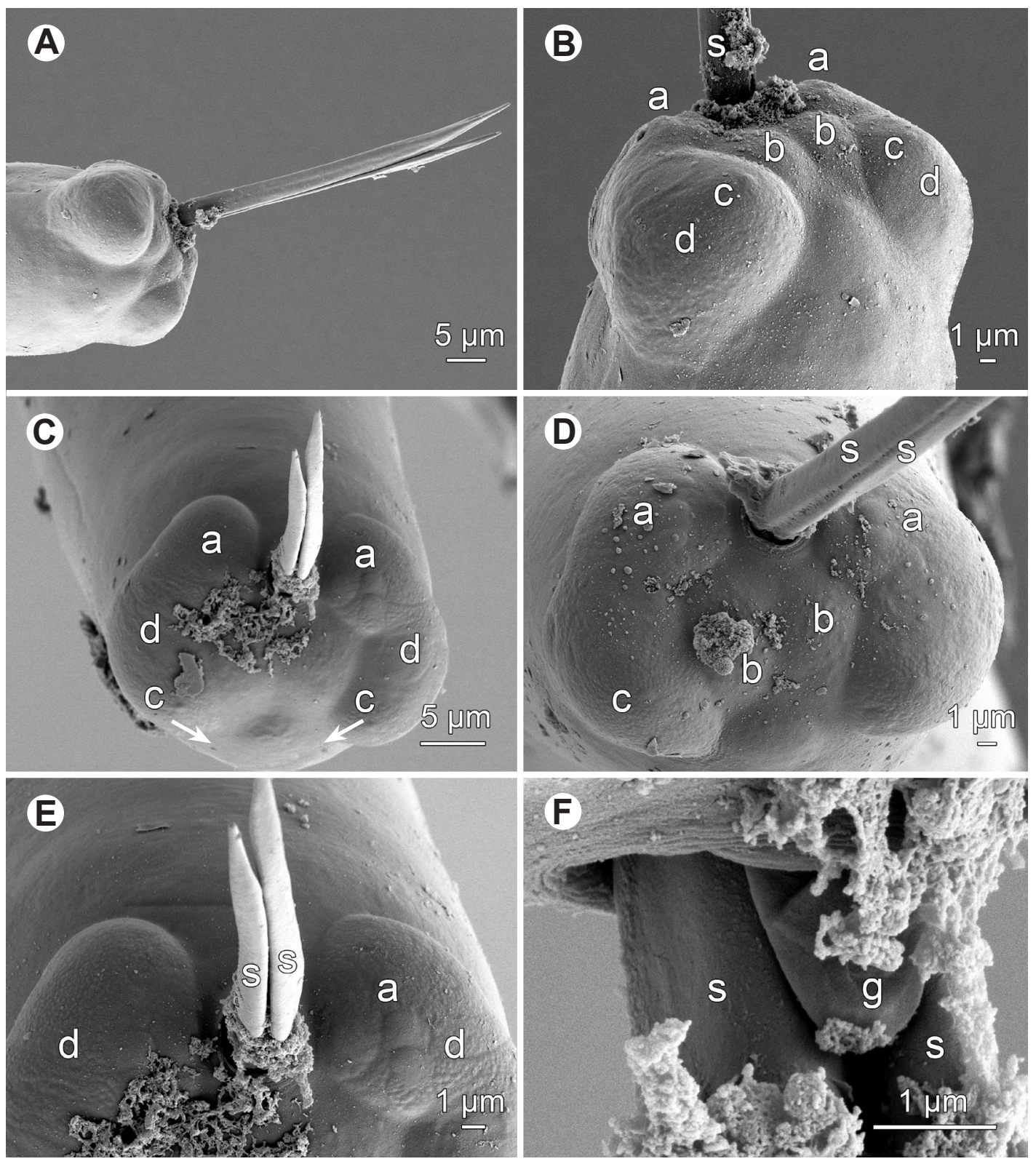

Fig. 4. Philometra sphyraenae sp. n., scanning electron micrographs of male. A, B - posterior end of body, sublateral and subdorsal views; $\mathbf{C}$ - caudal end, apical view (arrows indicate phasmids); $\mathbf{D}$ - same (another specimen), apical view; $\mathbf{E}$ - region of cloacal opening, apical view; F - region of cloacal opening, dorsal view. Abbreviations: a - group of flat caudal papillae near cloacal opening; $b$ - caudal papilla of ventral postanal pair; $\mathrm{c}$ - caudal papilla of second subventral postanal pair; $\mathrm{d}$ - caudal mound; $\mathrm{g}$ - gubernaculum; $\mathrm{s}-$ spicule.

and oesophageal nucleus $136-150$ and 326-367, respectively, from anterior extremity. Intestinal ligament 299 long. Vulva and vagina absent. Uterus empty.

Type host: Pickhandle barracuda, Sphyraena jello Cuvier (Sphyraenidae, Perciformes) (body length 68-71 cm).

Type locality: Bay of Bengal, off eastern coast of India (date of collection January-December 2010).

Site of infection: Gonad (ovary).

Prevalence and intensity: Larger females only: 69\% (182 fish infected/264 fish examined); mean intensity 9 nematode specimens per fish. Two fixed fish ovaries contained one gravid female and 19 males and seven gravid, subgravid and nongravid female nematodes, respectively.

Deposition of type specimens: Holotype (male), allotype (female) and 19 paratypes (12 males, seven females) in the Helminthological Collection of the Institute of Parasitology, Biology Centre of the Academy of Sciences of the Czech Republic, České Budějovice (Cat. No. N-1000).

Etymology: The specific name of this nematode relates to the genitive form of the generic name of the host.

Remarks. According to Moravec et al. (2011a), there are 32 gonad-infecting species of Philometra parasitizing 
marine and brackish-water fishes (the authors considered $P$. sawara Quiazon, Yoshinaga et Ogawa, 2008 a junior synonym of P. scomberomori [Yamaguti, 1935]). However, an additional species, $P$. atlantica Moravec, Bakenhaster et de Buron, 2013, has been described since (Moravec et al. 2013).

In having a smooth posterior end of the gubernaculum, the new species can be differentiated from the following 12 species, in which the posterior end of the gubernaculum bears numerous dorsal or lateral transverse lamella-like structures: P. brevicollis Moravec et Justine, 2011, P. charlestonensis Moravec, de Buron, Baker et González-Solís, 2008, P. cyanopodi Moravec et Justine, 2008, P. genypteri Moravec, Chávez et Oliva, 2011, P. lateolabracis, P. madai Quiazon, Yoshinaga et Ogawa, 2008, P. nemipteri Luo, 2001, P. priacanthi Moravec et Justine, 2009, P. saltatrix Ramachandran, 1973, P. sciaenae Yamaguti, 1941, P. scomberomori and $P$. terapontis (see Quiazon et al. 2008a,b, Moravec et al. 2008, 2011a,b, Moravec and Justine 2009, 2011).

Such structures were not described for other 12 gonadinfecting species of Philometra, for which the males are known. Of them, $P$. atlantica, $P$. carolinensis Moravec, de Buron et Roumillat, 2006 and P. floridensis Moravec, Fajer-Avila et Bakenhaster, 2010 differ markedly from the new species in possessing one or two reflexed dorsal barbs on the distal end of the gubernaculum, whereas all other species, except for P. mexicana Moravec et Salgado-Maldonado, 2007, can be distinguished by distinctly shorter or longer spicules: $P$. cephalus (spicules 74-116 long), P. fasciati Moravec et Justine, 2008 (147-156), $P$. filiformis (Stossich, 1896) (90-93), P. globiceps (Rudolphi, 1819) (137-156), P. jordanoi (López-Neyra, 1951) (260-265), P. lethrini Moravec et Justine, 2008 (108-111), P. mira Moravec et Justine 2011 (96-105) and $P$. tenuicauda Moravec et Justine, 2009 (245-249).

Philometra mexicana, a parasite of Epinephelus adscensionis (Osbeck) (Serranidae) in the Gulf of Mexico, has spicules 90-120 long (vs 120-132), but in contrast to the new species, its gravid female possesses a distinct bulbous inflation on the anterior end of the oesophagus and a pair of small lateral papilla-like caudal projections. A dorsal protuberance on the distal end of the gubernaculum similar to that in the new species has been described only for $P$. tenuicauda, but this species differs in having much longer spicules (see above).

Seven gonad-infecting species of Philometra, $P$. inimici Yamaguti, 1941, P. managatuwo Yamaguti, 1941, P. neolateolabracis [species inquirenda], P. neptomeni Mateo, 1972, P. rajani, P. sebastisci Yamaguti, 1941 and $P$. serranellicambrillae Janiszewska, 1949, are known only from females with a rather uniform morphology. Conspecific males have not subsequently been discovered for these nominal species. However, in contrast to the new species, gravid females of all these species are noted for the well-developed bulbous inflation of the anterior end of the oesophagus. Moreover, $P$. rajani can be differentiated by the presence of spines on the caudal end of the gravid female, the body length of gravid females of P. scomberomori $(150 \mathrm{~mm}), P$. sebastisci $(100-135 \mathrm{~mm})$ and $P$. serranellicabrillae $(40-60 \mathrm{~mm})$ is distinctly shorter, and the larvae of $P$. inimici (310-424), P. scomberomori (400), P. sebastisci (264-350) and P. serranellicabrillae (405-495) are shorter than 500 (vs 544-585 in the new species). None of the above-mentioned species has been reported from fishes of the family Sphyraenidae and from the Indian Ocean.

The only previous records of philometrids in fishes of the Sphyraenidae were those of Parukhin (1971), who had recovered female body fragments of these nematodes designated as Philometra sp. II in Sphyraena japonica Cuvier and $S$. genie Klunzinger from the Monar Bay and the Gulf of Aden, respectively (see also Moravec 2006). Since the site of infection of this Philometra sp. was not provided, it cannot be excluded that it was conspecific with $P$. sphyraenae.

Philometra gerrei sp. $\mathrm{n}$.

Figs. 5, 6

Male (four specimens; measurements of holotype in parentheses): Body filiform, whitish, 2.46-2.80 (2.49) $\mathrm{mm}$ long, maximum width at middle 60-66 (60); anterior part of body markedly narrower than middle and posterior parts, with slightly outlined narrower neck portion (Fig. 5C); body width at this narrower neck part 30-33 (33). Maximum width/body length $1: 39-42$ $(1: 42)$; width of cephalic end 33-39 (33), that of posterior end 36-42 (36). Cuticle smooth. Cephalic end rounded. Oral aperture small, triangular, surrounded by 14 small cephalic papillae arranged in two circles: external circle formed by four submedian pairs of papillae (each pair consisting of one circular and one narrower, more elongate papilla); internal circle by four submedian and two lateral papillae. Small lateral amphids just posterior to lateral papillae of internal circle (Figs. 5E, 6B). Oesophagus 341-507 (341) long, comprising 14-21\% (14\%) of body length, without inflation at anterior end; posterior part of muscular oesophagus overlapped by well developed oesophageal gland with large cell nucleus in middle (Fig. 5C). Oesophageal nucleus and nerve ring 267-321 (294) and 150-171 (150), respectively, from anterior extremity. Excretory pore 180-201 (180) from anterior end. Testis reaching anteriorly nearly to level of nerve ring (Fig. 5C). Posterior end of body blunt, with broad, two-lobed, kidney-shaped, lateral mounds; dorsal ends of these mounds far from each other (Figs. 5G, 6C,E). One pair of preanal, two pairs of adanal and one pair of postanal very flat, hardly visible caudal papillae close to each other near cloacal aperture on mounds (Figs. 5G, 6C-F); additional pair of small postanal papillae present on dorsal ends of mounds; pair of larger ventral papillae situated 

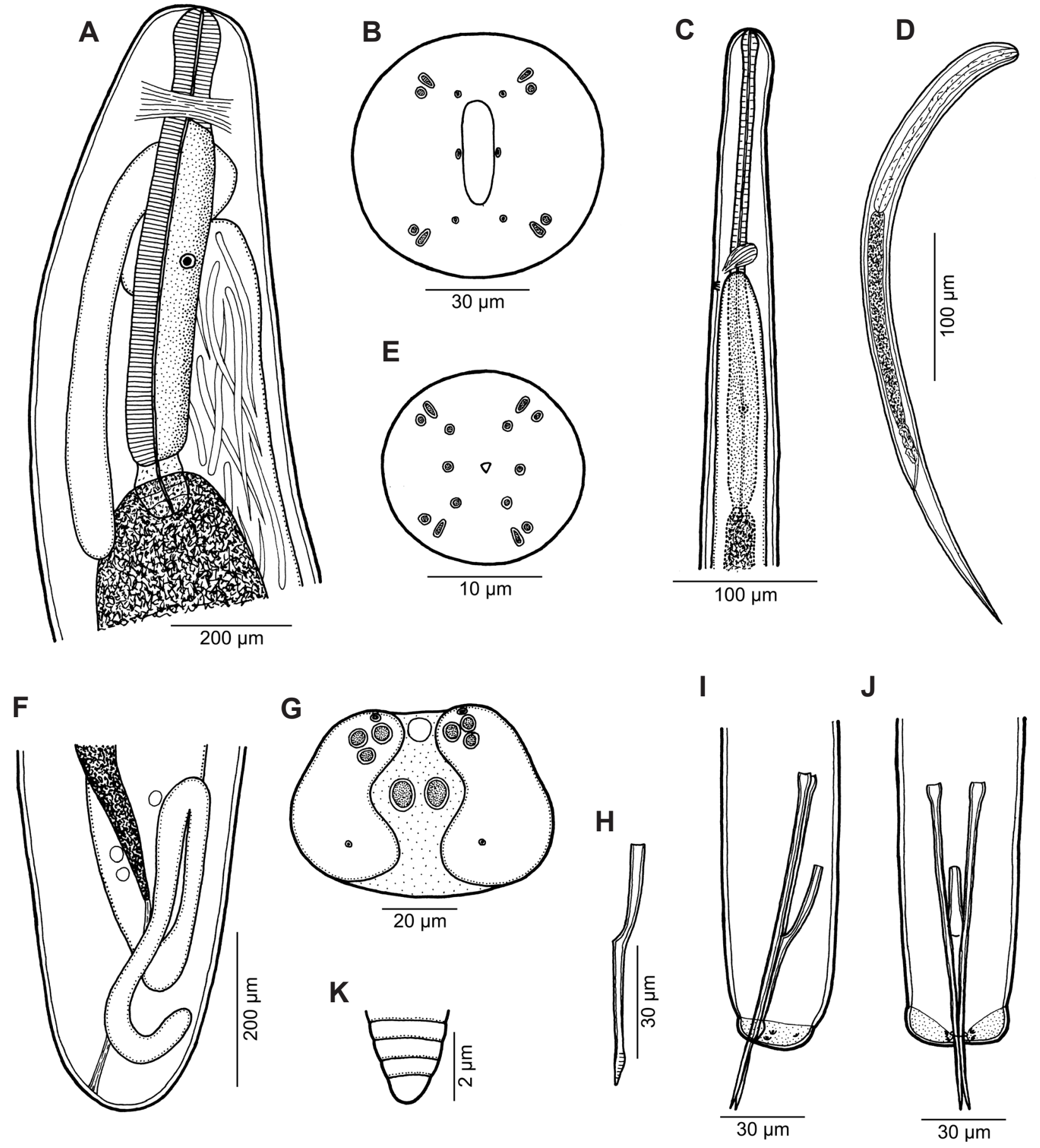

Fig. 5. Philometra gerrei sp. n. A - anterior end of gravid female, lateral view; $\mathbf{B}$ - cephalic end of gravid female, apical view; $\mathbf{C}$ - anterior end of male, lateral view; D - larva from uterus, lateral view; $\mathbf{E}$ - cephalic end of male, apical view; $\mathbf{F}$ - posterior end of gravid female, lateral view; $\mathbf{G}$ - caudal end of male, apical view (schematized); H - gubernaculum - lateral view; I, J - posterior end of male, lateral and ventral views; $\mathbf{K}$ - distal end of gubernaculum, dorsal view.

posterior to cloacal aperture, at level of middle part of lateral mounds (Figs. 5G, 6C,E). Phasmids not observed. Spicules slender, needle-like, equal or slightly subequal, with somewhat expanded proximal and sharply pointed distal tips (Figs. 5I,J); length of spicules 123-132 (132), comprising 4.5-5.3\% (5.3\%) of body length. Gubernacu- lum narrow, 72-78 (72) long, with anterior portion somewhat dorsally bent; length of anterior bent part 30-33 (30), representing 38-44\% (42\%) of entire gubernaculum length; posterior end of gubernaculum rounded, with dorsal protuberance and numerous transverse lamella-like structures (Figs. 5H-K, 6E,F). Length ratio of gubernacu- 

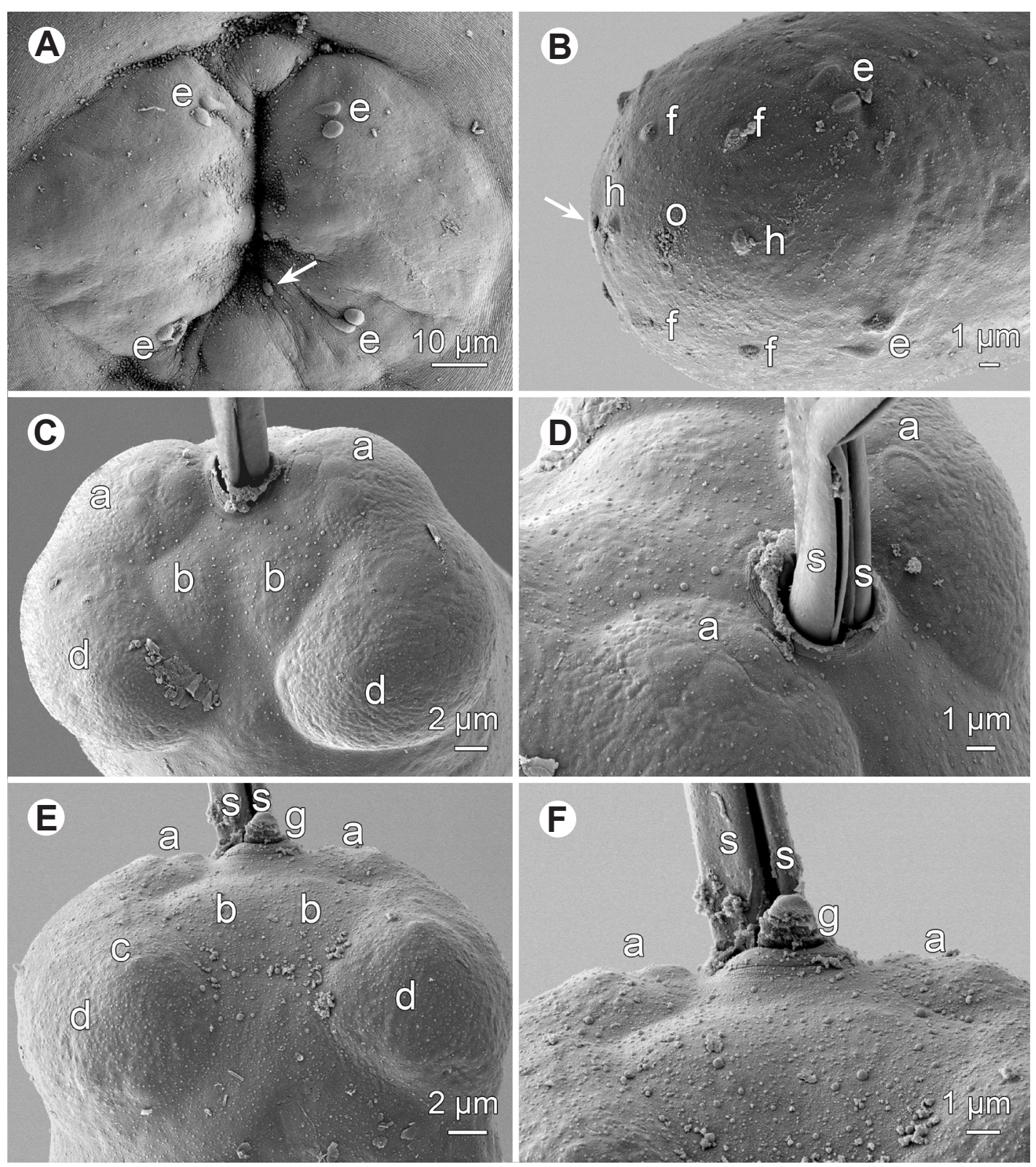

Fig. 6. Philometra gerrei sp. n., scanning electron micrographs. A - cephalic end of gravid female, apical view (arrow indicates submedian papilla of internal circle; remaining internal papillae not visible); $\mathbf{B}$ - cephalic end of male, subapical view (arrow indicates amphid); C - caudal end of male, apical view; $\mathbf{D}$ - region of cloacal opening, subapical view; $\mathbf{E}$ - caudal end of male, dorsal view; F - region of cloacal opening, dorsal view. Abbreviations: a - group of flat caudal papillae near cloacal opening; $\mathrm{b}$ - caudal papilla of ventral postanal pair; c - caudal papilla of second subventral postanal pair; $\mathrm{d}$ - caudal mound; $\mathrm{e}$ - submedian pair of external cephalic papillae; $\mathrm{f}$ - submedian cephalic papilla of internal circle; $\mathrm{g}$ - gubernaculum; $\mathrm{h}$ - lateral cephalic papilla of internal circle; $\mathrm{o}$ - oral aperture; $\mathrm{s}$ - spicule.

lum and spicules $1: 1.62-1.83(1: 1.83)$. Spicules and gubernaculum well sclerotized, yellowish, anterior part of gubernaculum colourless.

Gravid female (four complete and two incomplete larvigerous specimens; measurements of allotype in parentheses): Body of fixed specimens whitish, with distinct dark-brown intestine visible through cuticle, with rounded ends. Posterior part of body narrower than anterior part; maximum width in region posterior to oesophagus.
Cuticle smooth. Body length 114-386 (386) mm, maximum width $0.52-1.36(1.36) \mathrm{mm}$, maximum width/body length ratio $1: 139-284(1: 284)$. Width of cephalic end 204-544 (544). Cephalic papillae small, indistinct when viewed laterally (Fig. 5A). Oral aperture oval to somewhat triangular, surrounded by four pairs of submedian cephalic papillae of external circle and six single papillae (two lateral and four submedian) of internal circle (Figs. 5B, 6A). Amphids indistinct. 
Oesophagus including slightly outlined anterior bulbous inflation $0.86-1.33$ (1.33) mm long, comprising $0.3-0.8 \%(0.3 \%)$ of body length; bulb almost indistinct, 82-109 (82) long and 82-95 (82) wide; maximum width of oesophagus including gland 93-136 (136). Oesophageal gland relatively narrow, opening into oesophagus just posterior to nerve ring, with large cell nucleus in middle (Fig. 5A). Nerve ring and oesophageal nucleus 190-245 (245) and 476-694 (694), respectively, from anterior extremity. Small ventriculus 41-54 (54) long and 68-95 (95) wide. Oesophagus opening into intestine through distinct valve (Fig. 5A). Intestine narrow at anterior end; its posterior end narrow, attached by ligament ventrally to body wall near caudal end (Fig. 5F); ligament 272-1360 (1360) long.

Vulva and anus atrophied. Ovaries relatively short, thick, reflected, situated near body ends (Fig. 5A,F). Uterus occupying most space of body, filled with numerous larvae with long, slender tail (Fig. 5D); larvae $(n=5)$ in one paratype 456-489 long and 15-18 wide; length of oesophagus 99-141, of tail 90-108, representing 21-31\% and $19-23 \%$, respectively, of entire body length of larva. Posterior end of female rounded, 272-544 (408) wide, without any caudal projections (Fig. 5F).

Subgravid female (one complete and one incomplete ovigerous specimens): Body length $138 \mathrm{~mm}$, maximum width 204-830; maximum width/length ratio $1: 166$. Width of anterior end 95-231, of posterior end 245. Entire oesophagus 748-925 long, representing $0.7 \%$ of body length, and 122 wide. Anterior oesophageal bulb $82 \times 82$, ventriculus $24 \times 69$. Nerve ring and oesophageal nucleus 218 and 517, respectively, from anterior extremity. Intestinal ligament $1.77-2.79 \mathrm{~mm}$ long. Vulva and vagina absent. Uterus filled with many eggs.

Nongravid female (one specimen): Body length $10.57 \mathrm{~mm}$, maximum width 204; maximum width/length ratio 1: 52. Width of anterior end 95, of posterior end 95 . Entire oesophagus 748 long, representing 7\% of body length, and 54 wide. Anterior oesophageal bulb $68 \times 54$. Nerve ring 105 from anterior extremity. Vulva and vagina absent. Uterus empty.

Type host: Whipfin silver-biddy, Gerres filamentosus Cuvier (Gerreidae, Perciformes) (body length 18-24 cm).

Type locality: Bay of Bengal, off eastern coast of India (date of collection January-December 2010).

Site of infection: Gonad (ovary).

Prevalence and intensity: Larger females only: 91\% (192 fish infected/210 fish examined); 7-11 nematode specimens per fish. Of two fixed fish ovaries, one contained one male and a female body fragment, whereas the other one three males.

Deposition of type specimens: Holotype (male), allotype (female) and nine paratypes (one male, eight females) in the Helminthological Collection of the Institute of Parasitology, Biology Centre of the Academy of Sciences of the Czech Republic, České Budějovice (Cat. No. N-1001).
Etymology: The specific name of this nematode relates to the genitive form of the generic name of the host.

Remarks. The general morphology and morphometry of both male and female specimens of this new species are almost identical with those of $P$. sphyraenae sp. n., but both species distinctly differ in the structure of the gubernaculum. Whereas the distal end of the gubernaculum of the latter species is smooth, without dorsal transverse lamella-like structures, that of $P$. gerrei sp. n. is provided with many dorsal transverse lamella-like structures. Small interspecific difference is also in the body length of larvae from uterus (456-489 in P. gerrei vs 544-585 in P. sphyraenae). Both species also differ in the family of their fish hosts (Gerreidae vs Sphyraenidae).

To date, 12 gonad-infecting species of Philometra are known to possess numerous dorsal or lateral transverse lamella-like structures on the posterior end of the gubernaculum (see above). Of them, the distinct dorsal protuberance near the distal extremity of the gubernaculum, which occurs in the new species, is also present only in $P$. lateolabracis, $P$. priacanthi and $P$. terapontis.

However, in contrast to the new species, the males of P. lateolabracis possess a testis extending anteriorly to the mid-way between the nerve ring and the oesophageal nucleus ( $v s$ nearly to the nerve ring), their nerve ring and oesophageal nucleus are less distant from the anterior extremity (30-116 vs 150-171 and 180-249 vs 267-321, respectively), and the oesophagus is usually longer (255-363 vs 341-507). The number and distribution of genital papillae was not described in P. lateolabracis, but, judging from illustrations, they seem to be different, as well as the structure of the cloacal opening. The oral opening of $P$. lateolabracis gravid females is triangular and small ( $v s$ elongate oval and large) and the larvae from uterus are somewhat shorter (385-433 vs 456-489), with a longer tail (27-30 vs 19-23\% of the body length) (Quiazon et al. 2008a).

The males of $P$. priacanthi are longer (3.01-3.60 vs $2.82-2.80 \mathrm{~mm}$ ), the male caudal mounds are dorsally separated, but with dorsal ends close to each other ( $v s$ dorsal ends of male caudal mounds far from each other), the proximal bent portion of the gubernaculum forms only $38-44 \%$ (vs $48-59 \%$ ) of the entire gubernaculum length, and the testis slightly exceeds anteriorly the posterior end of the oesophagus ( $v S$ extends nearly to the level of the nerve ring) (Moravec and Justine 2009).

The males of $P$. terapontis are somewhat longer (2.82-3.36 vs 2.46-2.80 mm) but their spicules are distinctly shorter (105-114 vs 123-132), the male caudal mounds are dorsally connected ( $v s$ widely separated), the testis extends anteriorly to about the oesophago-intestinal junction ( $v s$ nearly to the level of the nerve ring), the female posterior extremity bears two minute papilla-like caudal projections ( $v s$ caudal projections absent), and the anterior inflation of the female oesophagus is well devel- 
oped (vs poorly developed, almost absent) (Moravec et al. 2011a). Moreover, the hosts of all these three above mentioned species belong to other fish families than that of $P$. gerrei (Lateolabracidae, Priacanthidae and Terapontidae $v s$ Gerreidae).

As mentioned above, seven gonad-infecting species of Philometra are known only from females with a rather uniform morphology. However, in contrast to the new species, gravid females of all these species are noted for the well-developed bulbous inflation of the anterior end of the oesophagus. None of them has been reported from fishes of the family Gerreidae and from the Indian Ocean.

Philometra gerrei is the first species of the Philometridae reported from fishes belonging to the perciform family Gerreidae.

\section{Philometra otolithi sp. n.}

Figs. 7, 8

Gravid female (one larvigerous specimen): Body of fixed specimen yellowish with distinct brown intestine, $134 \mathrm{~mm}$ long and 911 in maximum width, markedly narrowed towards anterior extremity; maximum width/ length ratio of body $1: 147$; anterior part of body broader than posterior part; width of cephalic end 204, that of caudal end 150. Cuticle smooth. Cephalic end rounded, cephalic papillae small, almost indistinct in lateral view (Fig. 7A,B). Oral aperture circular, large, surrounded by 14 cephalic papillae arranged in two circles. External circle formed by four pairs of submedian papillae; papillae of each pair relatively far from each other, consisting of one circular and one more elongate papilla. Internal circle formed by four submedian single papillae and one pair of minute single lateral papillae (Figs. 7C, 8A). Lateral amphids outlined. Oral aperture followed by spacious buccal cavity formed by internal surface of anterior oesophageal inflation, bearing many conspicuous transverse lamellalike structures (Fig. 8B).

Oesophagus muscular, inflated at anterior end to form distinct bulb, 933 long, comprising $0.5 \%$ of body length (Fig. 7A). Oesophageal bulb 120 long and 153 wide, with spacious lumen. Greater, posterior part of oesophagus slightly expanded, maximum width of oesophagus including oesophageal gland 150. Latter not well demarcated, extending from posterior end of oesophagus to level of nerve ring; its poorly visible nucleus at 571 from anterior end of body. Small ventriculus 41 long and 68 wide, opening into intestine through valve (Fig. 7A). Nerve ring encircling oesophagus 245 from anterior extremity (Fig. 7A). Intestine brown, straight, ending blindly; anterior end of intestine relatively narrow; posterior end of intestine atrophied, forming ligament 1.27 long attached ventrally to body wall close to posterior extremity (Fig. 7E).

Ovaries short, reflexed, situated near anterior and posterior body ends (Fig. 7A, E). Uterus occupying major part of body, filled with numerous larvae and eggs. Lar- vae 426-459 long, maximum width 15-18; oesophagus $129-141$ long (28-32\% of body length), length of tail 96-111 (23-24\%); cuticle of larvae densely transversely striated, their cephalic end provided with large oral aperture surrounded by four submedian cephalic papillae, pair of large lateral amphids and conspicuous dorsal tooth (Figs. 7D, 8C-F). Posterior end of body of gravid female rounded, without any caudal projections (Fig. 7E).

Male: Unknown.

Type host: Tigertooth croaker, Otolithes ruber (Bloch et Schneider) (Sciaenidae, Perciformes) (body length 30-32 cm).

Type locality: Bay of Bengal, off eastern coast of India (date of collection January-December 2010).

Site of infection: Gonad (ovary).

Prevalence and intensity: Larger females only: 47\% (91 fish infected/194 fish examined); mean intensity 6 nematode specimens per fish. In one fixed fish ovary, one complete gravid female (in two parts) and a body fragment $11.4 \mathrm{~mm}$ long of another smaller (subgravid) female specimen without both body ends were found.

Deposition of type specimen: Holotype in the Helminthological Collection of the Institute of Parasitology, Biology Centre of the Academy of Sciences of the Czech Republic, České Budějovice (Cat. No. N-1002).

Etymology: The specific name of this nematode relates to the genitive form of the generic name of the host.

Remarks. Philometrids exhibit a rather high degree of host specificity (Rasheed 1963, Ivashkin et al. 1971, Moravec 2006) and individual species are characterized by their location in the host, particularly that of gravid females (Moravec 2004, Moravec et al. 2008). Moravec et al. (2013) reported a total of 33 species of Philometra, the gravid females of which are parasitic in the gonads of marine and brackish-water fishes; two additional nominal species, $P$. sphyranae sp. n. and P. gerrei sp. n., are described in this paper.

However, none of these gonad-infecting species has a large anterior oesophageal bulbous inflation with conspicuosly large buccal cavity similar to that in the new species. The large anterior oesophageal bulbous inflation with a spacious lumen was described in $P$. ivaschkini Parukhin, 1976, P. javaensis Moravec, Walter et Yuniar, 2012, P. lagocephali Moravec et Justine, 2008 and $P$. pellucida (Jägerskiöld, 1893), parasites of perciform and tetraodontiform fishes in the Indo-Pacific (Moravec 2006, Moravec and Justine 2008, Moravec et al. 2012a). However, in contrast to $P$. otolithi sp. n., none of them has the broad and deep buccal cavity provided with conspicuous transverse lamella-like structures (the bottom of their mouth is formed by flat surfaces of three anterior oesophageal lobes); moreover, gravid females of these species are parasites of the stomach wall or the abdominal cavity of the host.

Four gonad-infecting species of Philometra are known only by their males and conspecific gravid females re- 
B

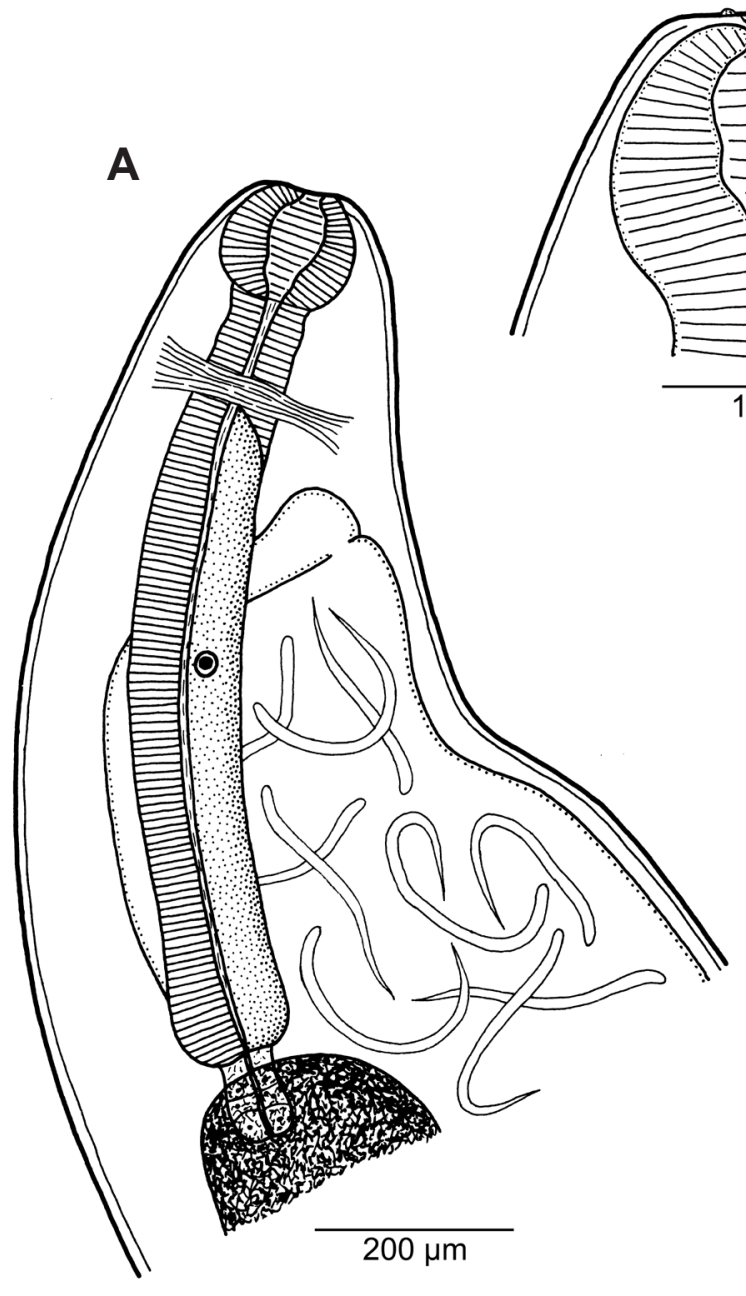

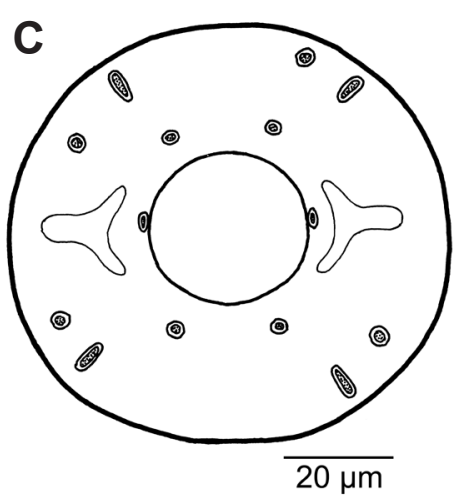

E
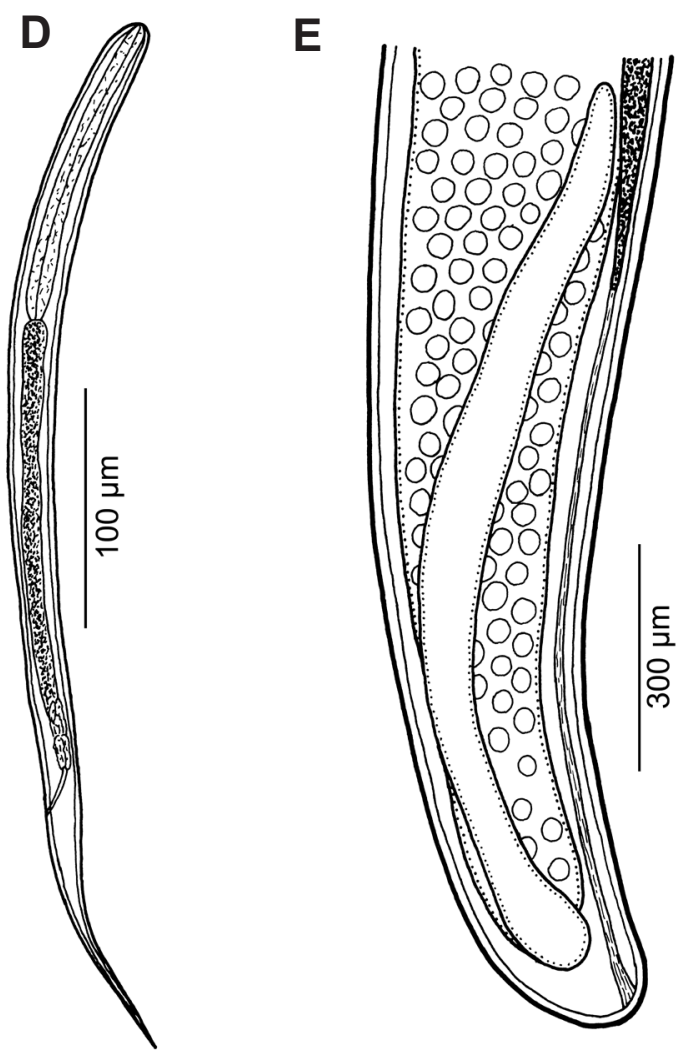

Fig. 7. Philometra otolithi sp. n., gravid female. A - anterior end of body, lateral view; B, C - cephalic end, lateral and apical views; $\mathbf{D}$ - larva from uterus, lateral view; $\mathbf{E}$ - posterior end of body, lateral view.

main unknown: P. katsuwoni Petter et Baudin-Laurencin, 1986, P. macroandri (Shchepkina, 1978), P. mira and P. priacanthi (see Moravec 2006, Moravec and Justine 2009, 2011). However, these species occur in hosts belonging to other fish families (Scombridae, Lutjanidae and Priacanthidae vs Sciaenidae).

Fishes of the perciform family Sciaenidae seem to be frequent hosts of philometrid nematodes, particularly those parasitic in the fish gonads (Moravec et al. 2006, 2007). To date, five nominal gonad-infecting species of Philometra have been reported from sciaenids: P. carolinensis, P. floridensis, P. lateolabracis, P. rajani, and $P$. sciaenae. However, even though $P$. lateolabracis was reported from several species of sciaenid fishes includ- ing Otolithes ruber, the type host of $P$. otolithi sp. n. (see Moravec 2006), with respect to the papers of Moravec (2008) and Quiazon et al. (2008a), all records of P. lateolabracis from these hosts were probably misidentifications and the parasites should be designated only as Philomet$r a$ sp. According to Quiazon et al. (2008a), P. lateolabracis is a specific parasite of Lateolabrax japonicus (Cuvier) (Lateolabracidae).

Philometra carolinensis from Cynoscion nebulosus (Cuvier) and Menticirrhus americanus (Linnaeus) and P. floridensis from Sciaenops ocellatus (Linnaeus), both from off the Atlantic coast and Gulf of Mexico, USA, differ from the new species mainly in the absence of a markedly large anterior oesophageal inflation in gravid 

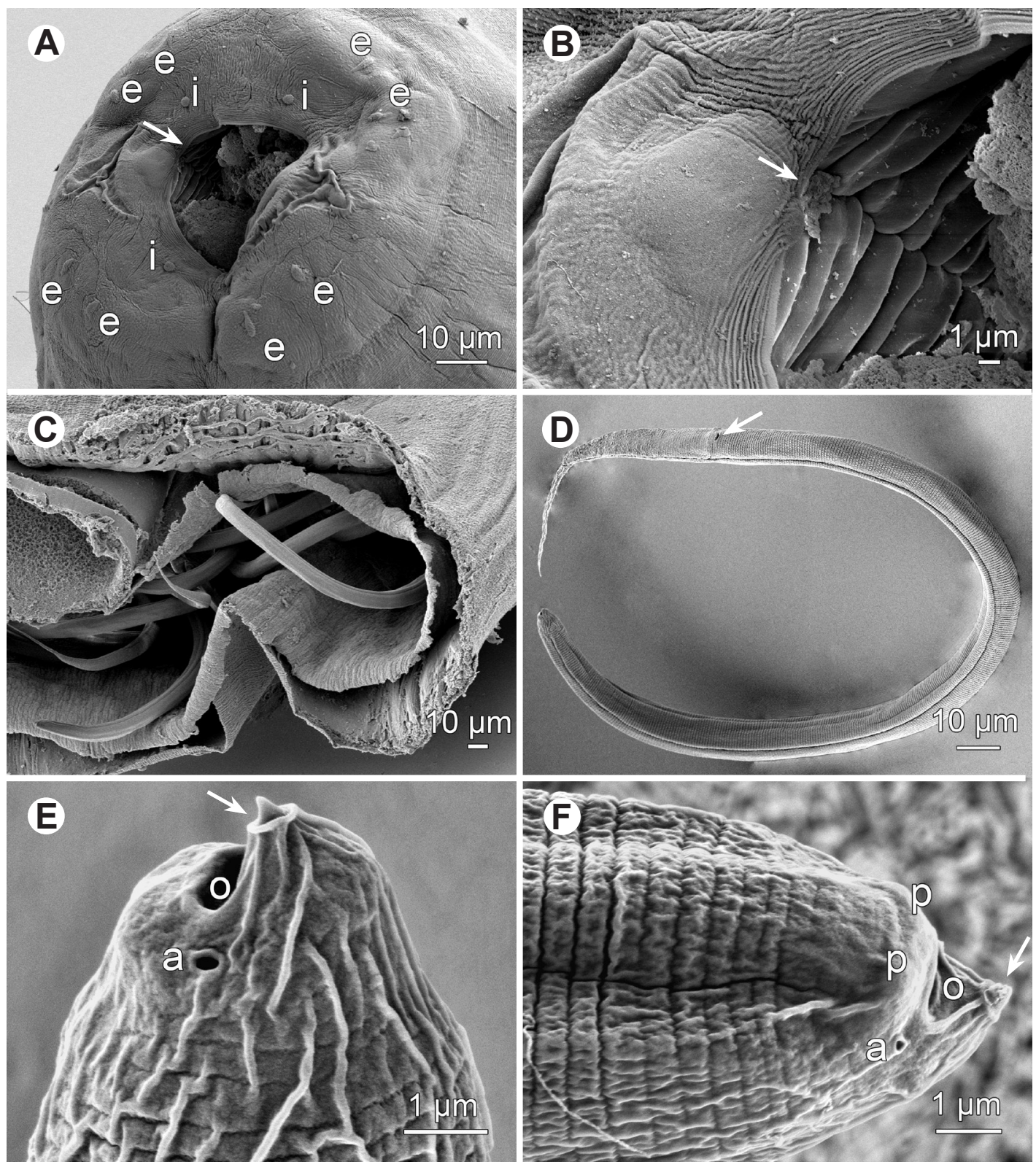

Fig. 8. Philometra otolithi sp. n., scanning electron micrographs. A - cephalic end of gravid female, apical view (arrow indicates minute lateral papilla of internal circle); B - detail of mouth of gravid female, apical view (arrow indicates minute lateral papilla of inner circle; note conspicuous transverse lamellae in buccal cavity); C - first-stage larvae in female's body; D - larva from uterus, lateral view (arrow indicates annal opening); $\mathbf{E}, \mathbf{F}$ - cephalic end of first-stage larva, lateral views (different specimens; arrow indicates dorsal cephalic tooth). Abbreviations: a - amphid; e - submedian cephalic papilla of external circle; $\mathrm{i}$ - submedian cephalic papilla of internal circle; $\mathrm{o}$ - oral aperture; $\mathrm{p}$ - submedian cephalic papilla of larva;

and large subgravid females (Moravec et al. 2006, 2010, Moravec and de Buron 2009). Also the large females of P. sciaenae from Pennahia argentata (Houttuyn) in the North Pacific Ocean and the South China Sea near Japan can be mainly distinguished from those of the new species by a moderately developed anterior oesophageal inflation without a spacious buccal cavity provided by numerous transverse lamellae (Yamaguti 1941, Moravec et al. 1998, Quiazon et al. 2008b).
Philometra rajani was inadequately described solely from females recovered from the gonads of Eleutheronema tetradactylum (Shaw) (Polynemidae) and Johnius coitor (Hamilton) (Sciaenidae) apparently from off the coast of southern India (locality not given) (Mukherjee 1963). Although the illustrated anterior oesophageal inflation somewhat resembles that of $P$. otolithi sp. n., the gravid female of $P$. rajani is much longer than that of $P$. otolithi (186-274 vs $134 \mathrm{~mm}$ ) and its caudal end allegedly bears small terminal spines ( $v s$ no caudal spines or projections 
present). Later P. rajani was reported by Mohan (1971) from Johnius dussumieri (Cuvier), J. belangerii (Cuvier), Nibea maculata (Bloch et Schneider) and Pennahia anea (Bloch) from the Palk Bay, southern India, but this species was subsequently synonymized with $P$. lateolabracis by Soota (1983). On the other hand, Sood (1989) listed it again as a valid species. However, because of the poor original description of $P$. rajani from hosts belonging to two different families, it is highly probable that Mukherjee's nematodes belonged in fact to two different species. The type host of $P$. rajani was not established but since E. tetradactylum was the first reported in the original paper, it can be taken for the type host of this species. In the situation when no type specimens are maintained, it is necessary to consider $P$. rajani a species inquirenda.

The authors are aware of the fact that $P$. otolith $i$ is being practically described from a single specimen, a procedure that cannot be generally recommended; however, in this case, the new species appears to be well established, and, therefore, they consider it more reasonable and useful to give it a specific name than to report it as Philometra sp.

\section{Philometra sp.}

Figs. 9, 10

Subgravid female (based on one complete and two incomplete specimens): Body of fixed specimens whitish, with distinct dark-brown intestine visible through cuticle, with rounded ends. Posterior part of body narrower than anterior part; maximum width in region posterior to oesophagus. Cuticle smooth. Body length of one complete specimen $62 \mathrm{~mm}$, of one incomplete specimen without anterior end (half of oesophagus missing) $48 \mathrm{~mm}$, and one anterior body fragment $24 \mathrm{~mm}$ long; maximum width 313-462; maximum width/body length ratio in complete specimen $1: 134$. Width of cephalic end 122-163 and of caudal end 163. Cephalic papillae small, almost indistinct when viewed laterally (Fig. 9A,B).

Oral aperture oval, large. Four pairs of submedian cephalic papillae of external circle (each pair composed of one almost circular papilla and one more elongate papilla) and four submedian single papillae of internal circle present (Figs. 9C, 10A); pair of lateral single papillae probably also present but not visible on SEM micrographs. Amphids outlined. Bottom of mouth formed by lobes of three oesophageal sectors. Oesophagus including moderately developed anterior bulbous inflation 653-884 long, comprising $1.4 \%$ of body length in complete specimen; bulb 90-114 long and 69-99 wide; maximum width of oesophagus including gland 68-95. Oesophageal gland relatively narrow, opening into oesophagus just posterior to nerve ring, with cell nucleus in middle (Fig. 9A).

Nerve ring and oesophageal nucleus 174-272 and 394-558, respectively, from anterior extremity. Small ventriculus 15-24 long and 39-63 wide. Oesophagus opening into intestine through distinct valve (Fig. 9A). Intestine narrow at anterior end; its posterior end narrow, attached by ligament ventrally to body wall near caudal end (Fig. 9D,E); ligament 190-204 long. Vulva and anus atrophied. Ovaries relatively short, reflected, situated near body ends. Uterus containing numerous eggs. Posterior end rounded, without any caudal projections (Figs. 9D,E, 10B).

\section{Male: Unknown.}

Host: Belanger's croaker, Johnius belangerii (Cuvier) (Sciaenidae, Perciformes) (body length $26-34 \mathrm{~cm}$ ).

Type locality: Bay of Bengal, off eastern coast of India (date of collection January-December 2010).

Site of infection: Gonad (ovary).

Prevalence and intensity: Larger females only: 48\% (174 fish infected/362 fish examined); mean intensity 8 nematode specimens per fish. Of four fixed fish ovaries, two contained one and two subgravid female nematodes.

Deposition of voucher specimens: Three female specimens in the Helminthological Collection of the Institute of Parasitology, Biology Centre of the Academy of Sciences of the Czech Republic, České Budějovice (Cat. No. N-1003).

Remarks. Since only a few subgravid nematode specimens are available, their species identification based on morphological features is impossible. It has been mentioned above that Mohan (1971) reported the gonad-infecting species Philometra rajani [species inquirenda] from the same fish host, Johnius belangerii, from the Palk Bay, southern India. Therefore, it is highly probable that Mohan's specimens from this host species and those of the present material have represented one and the same species. However, further studies are necessary to determine the actual species allocation of these nematodes.

\section{Philometroides eleutheronemae sp. n. Figs. 11, 12}

Subgravid female (three specimens, measurements of holotype in parentheses): Body of fixed specimens whitish, filiform, 44-78 (65) mm long and 802-857 (802) in maximum width; maximum width/length ratio of body $1: 54-81$ (1:81). Width of cephalic end 245-272 (272), that of caudal end 190-272 (272). Entire body with sparsely distributed small cuticular bosses 3-6 (3-6) high on surface (Fig. 11D,E); bosses absent in oesophageal region and rarely scattered on rest of body. Anterior end of body truncated in dorsoventral view, with distinctly depressed cephalic extremity bearing two small lateral elevated protuberances (Figs. 11A,B,C, 12A,B). Oral aperture oval. Cephalic papillae small, indistinct in lateral or dorsoventral views, probably arranged in two circles; only four submedian pairs of external circle (each pair consisting of one circular and one more elongate papilla) visible on SEM micrograph, whereas papillae of internal circle probably overlapped by present impurities (Figs. 11C, 12B). Two marked lateral protuberances situated near oral aperture present, amphids indistinct (Figs. 11C, 12A,B).

Oesophagus muscular, with moderately developed elongate bulbous inflation, 1.59-1.74 (1.67) mm long, 

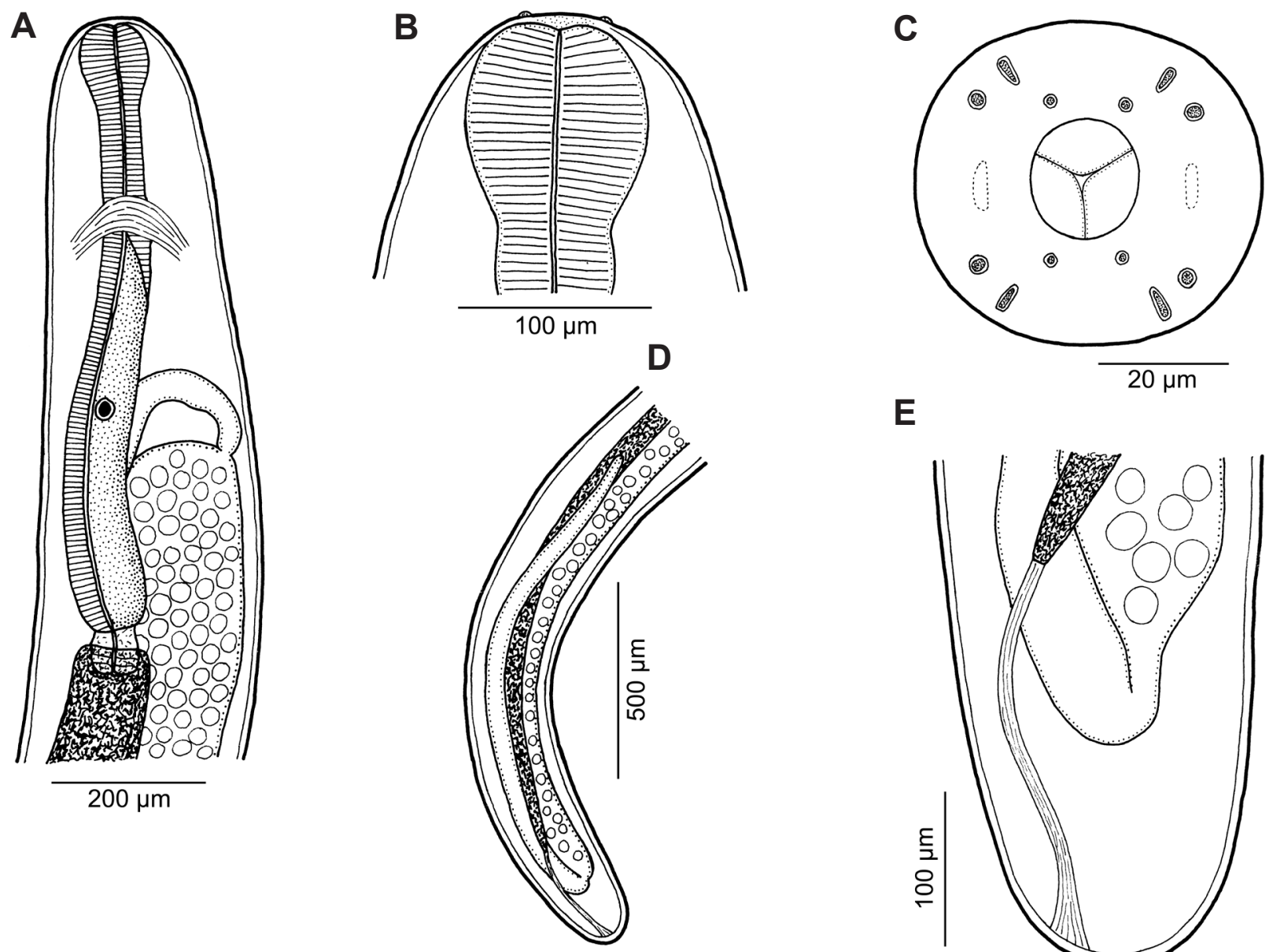

E

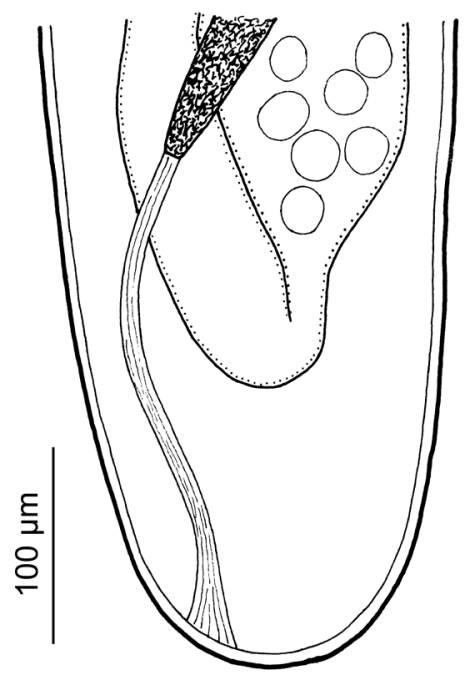

Fig. 9. Philometra sp., subgravid female from Johnius belangerii. A - anterior end of body, lateral view; $\mathbf{B}, \mathbf{C}$ - cephalic end, lateral and apical views; $\mathbf{D}$ - posterior end of body, lateral view; $\mathbf{E}$ - caudal end of body, lateral view.
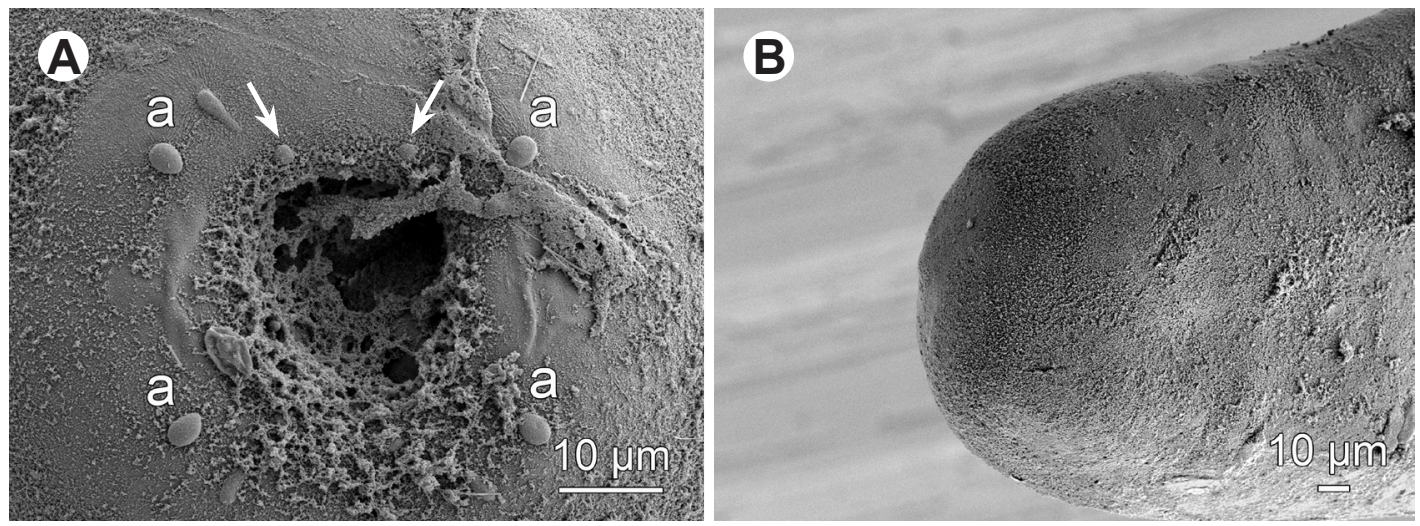

Fig. 10. Philometra sp., scanning electron micrographs of subgravid female from Johnius belangerii. A - cephalic end, apical view (arrows indicate submedian cephalic papillae of internal circle; internal lateral papillae not visible); B - caudal end, lateral view. Abbreviation: a - submedian pair of cephalic papillae of external circle.

comprising $1.2-2.0 \%(1.6 \%)$ of body length (Fig. 11A); maximum width of posterior portion of oesophagus 136-150 (150). Anterior oesophageal inflation 150-204 (204) long and 114-136 (136) wide. Oesophageal gland little developed, starting at level of nerve ring and extend- ing posteriorly nearly to end of oesophagus (Fig. 11A); nucleus of oesophageal gland 571-694 (694) mm from anterior end of body. Small ventriculus 30-51 (51) long and 102-105 (105) wide, opening into intestine through valve (Fig. 11A). Nerve ring 313-340 (340) from anterior 

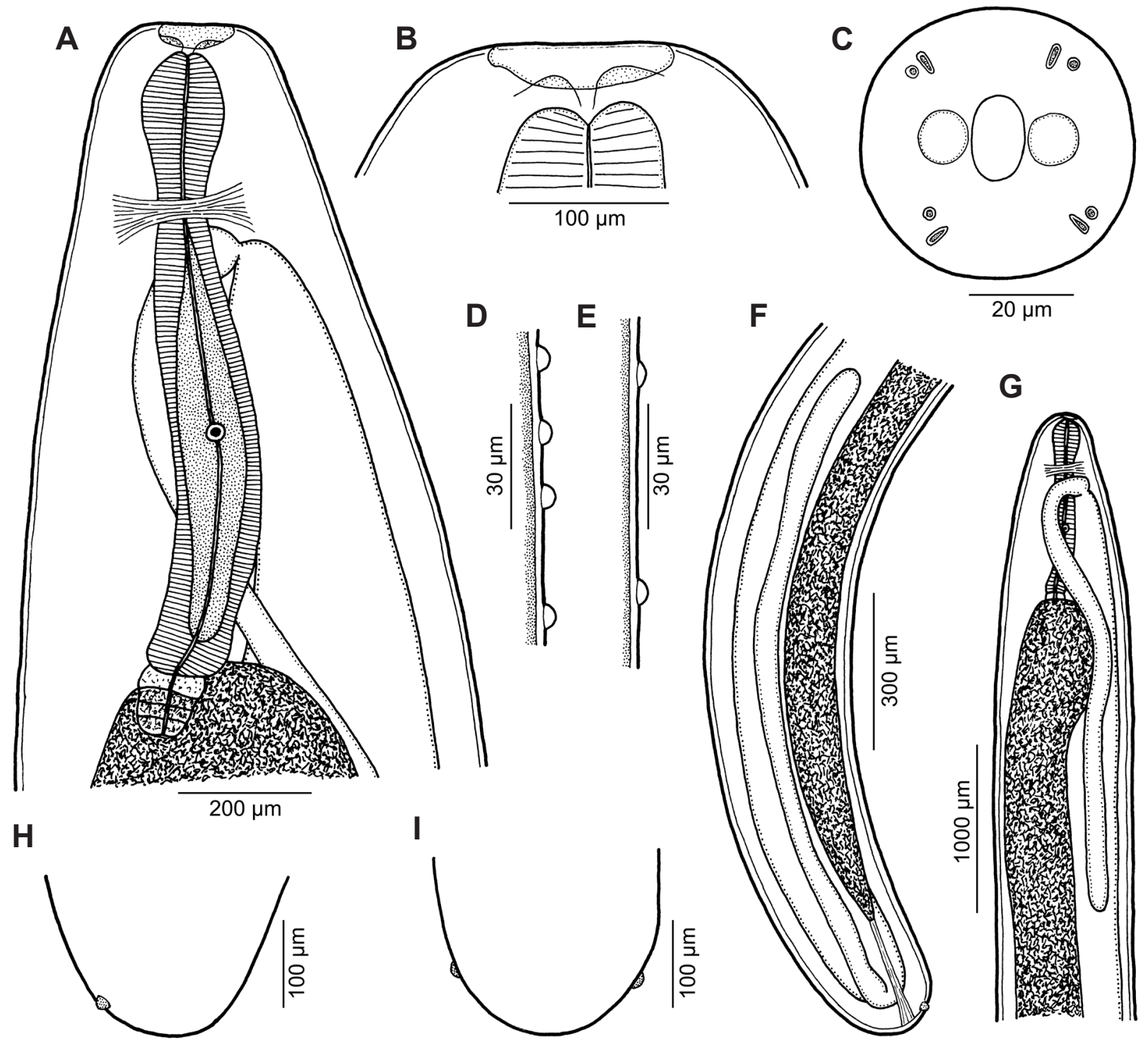

Fig. 11. Philometroides eutheronemae sp. n., subgravid female. A - anterior end of body, dorsoventral view; $\mathbf{B}, \mathbf{C}-\mathrm{cephalic}$ end, dorsoventral and apical views; $\mathbf{D}, \mathbf{E}$ - cuticular bosses on body surface, lateral views; $\mathbf{F}, \mathbf{G}$ - posterior and anterior body ends, lateral views; H, I - caudal end, lateral and dorsoventral views.

extremity. Intestine dark-brown, straight; posterior end of intestine atrophied, forming ligament 231-1060 (1060) long, attached to posterior extremity (Fig. 11F). Posterior end of body rounded, provided with pair of small lateral papilla-like caudal projections (Fig. 11F,H,I). Ovaries long, situated near anterior and posterior body ends (Fig. 11A,F,G). Uterus extending anteriorly to about level of nerve ring, containing numerous eggs.

Male: Unknown.

Type host: Fourfinger threadfin, Eleutheronema tetradactylum (Shaw) (Polynemidae, Perciformes) (body length 39-44 cm). Type locality: Bay of Bengal, off eastern coast of India (date of collection January-December 2010).

Site of infection: Gonad (ovary).

Prevalence and intensity: 52\% (99 fish infected/192 fish examined); mean intensity five nematodes per fish. Of one fixed ovary, three fragmented female specimens were obtained.

Deposition of type specimens: Holotype (female) and two paratypes (females) in the Helminthological Collection of the Institute of Parasitology, Biology Centre, Academy of Sciences of the Czech Republic, in České Budějovice (Cat. No. N-1004).

Etymology: The specific name of this nematode relates to the genitive form of the generic name of the type host.

Remarks. In having the body surface with irregularly distributed small papilla-like bosses, the female specimens of the present material belong to the philometrid genus Philometroides Yamaguti, 1935 (see Moravec 2006). According to Moravec et al. (2012b), at present this genus 

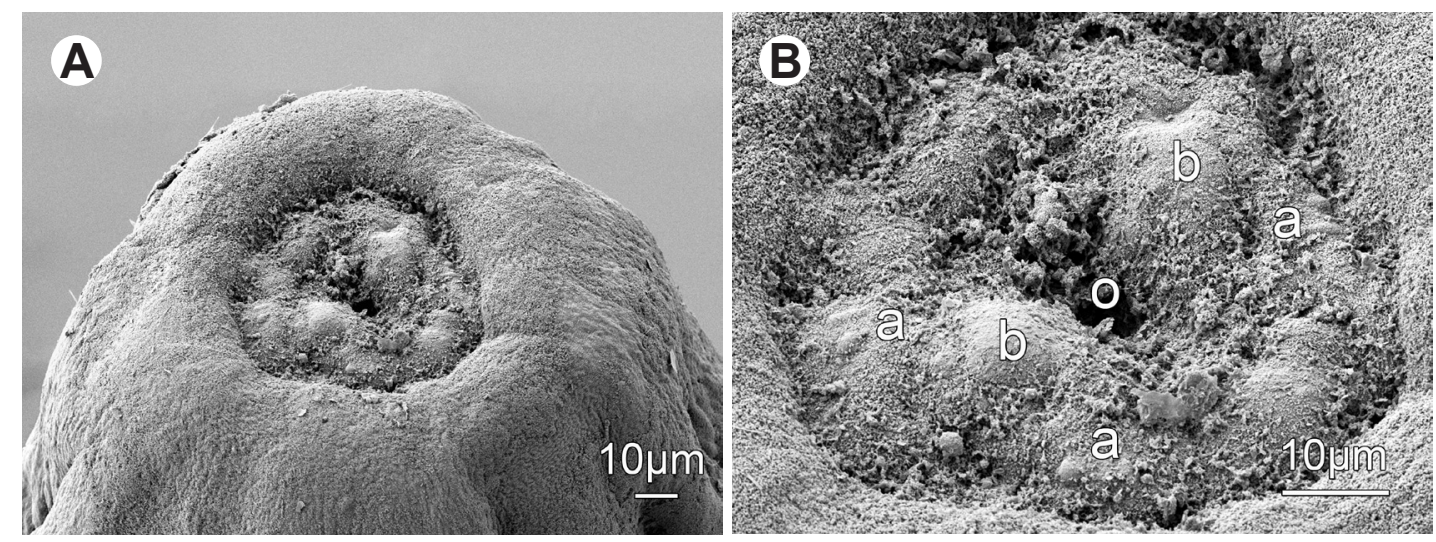

Fig. 12. Philometroides eutheronemae sp. n., scanning electron micrographs of subgravid female. $\mathbf{A}$ - anterior end of body, subapical view; B - depressed anterior extremity, apical view. Abbreviations: a - submedian pair of cephalic papillae of external circle; $\mathrm{b}$ - lateral cephalic protuberance; $\mathrm{o}$ - oral aperture.

comprises 30 valid species, the majority of which (19) are parasites of freshwater fishes, whereas only ten have been described from marine fishes and one from a brackish-water fish. Most of them were described only from females, whereas conspecific males are known for eight species. As other philometrids, Philometroides spp. are known to exhibit a relatively high degree of host specificity, and individual species are characterized, in addition to morphological and sequence data, by the location of subgravid and gravid females in the host (Moravec 2006, Moravec et al. 2012a).

The following species of Philometroides are known as parasites of marine and brackish-water fishes: P. acanthopagri Moravec, Jassim et Al-Salim, 2012, P. atropi (Parukhin, 1966), P. branchiostegi Moravec, Nagasawa et Nohara, 2012, P. denticulatus Rasheed, 1965, P. grandipapillatus Moravec et Bakenhaster, 2010, P. indonesiensis Moravec, Walter et Yuniar, 2012, P. marinus Moravec et de Buron, 2009, P. oveni Parukhin, 1975, P. paralichthydis Moravec et de Buron, 2006, P. seriolae (Ishii, 1931) and P. trichiuri Moravec, Walter et Yuniar, 2012. Except for $P$. indonesiensis and $P$. paralichthydis, they are all parasites of Perciformes (see Moravec 2006, Moravec and de Buron 2009, Moravec and Bakenhaster 2010, Moravec et al. 2012a,b,c).

The new species differs from all of them in the character of the cuticular embossment, particularly in the absence of bosses from the oesophageal region of the body, in the presence of small caudal projections, and in the combination of some other morphological and biometrical features as is evident from the key provided by Moravec et al. (2012c). Moreover, Philometroides eutheronemae sp. $\mathrm{n}$. differs from all other congeners by the location in the host (gonads $v s$ abdominal cavity, musculature, subcutaneous tissues, fins, swimbladder, stomach wall or eyes). It is the first representative of Philometroides reported from a fish belonging to the family Polynemidae.
To date, only two nominal philometrid species were reported from fishes of the Polynemidae, both belonging to Philometra: P. polynemii Rasheed, 1963 from the abdominal cavity of Eleutheronema tetradactylum off the coast of Pakistan (Karachi) (Rasheed 1963) and P. rajani [species inquirenda] from the ovary of the same fish species probably off the coast of India (locality not given) (Mukherjee 1963). In addition to the absence of cuticular bosses, $P$. polynemii distictly differs from the new species by females possessing eight fleshy lobes arranged in four groups of two each, a flask-shaped oesophagus with a large oesophageal gland, and two large lateral caudal projections (Rasheed 1963), whereas $P$. rajani by females possessing a large anterior oesophageal bulb and allegedly spines on the caudal end (Mukherjee 1963).

However, the latter species was inadequately described from the same host species, localization in the host (ovary) and probably the same geographical region as the new Philometroides species and is now considered a species inquirenda (see above). Therefore, it cannot be excluded that both species are identical and that Mukharjee (1963) only overlooked minute cuticular bosses on the body of his nematodes and erroneously described their morphology. On the other hand, Moravec and Justine (2011) recorded two different gonad-infecting philometrid species in the same fish host, Lutjanus vitta (Quoy et Gaimard), from off New Caledonia. Further studies of Philometra rajani are needed.

Acknowledgements. We would like to express our gratitude to Prof. T. Balasubramanian, Dean, Faculty of Marine Sciences for his constant encouragement and the Annamalai University for the facilities provided during the study period. Authors' thanks are also due to the staff of the Laboratory of Electron Microscopy, Institute of Parasitology, Biology Centre of the AS CR, České Budějovice for their technical assistance, and to Blanka Škoríková of the same Institute for help with illustrations. This study was partly supported by the Czech Science Foundation (grant No. P505/12/G112) and the Institute of Parasitology, BC AS CR (institutional support RVO: 60077344). 
Froese R., Pauly D. (Eds.) 2012: FishBase. World Wide Web electronic publication. http://www.fishbase.org, version 05/2012.

Hesp S.A., Hobbs R.P., Ротter I.C. 2002: Infection of the gonads of Glaucosoma hebraicum by the nematode Philometra lateolabracis: occurrence and host response. J. Fish Biol. 60: 663-673.

Ivashrin V.M., Sobolev A.A., Khromova L.A. 1971: [Camallanata of Animals and Man and the Diseases Caused by Them. Osnovy nematodologii 22.] Nauka, Moscow, 388 pp. (In Russian.)

Kardousha M.M. 1999: The first record of Philometra lateolabracis Yamaguti, 1935 [sic!] (Nematoda: Spirurida; Philometridae) from teleost fishes of the Arabian Gulf. Qatar Univ. Sci. J. 18: $131-136$

Mohamed A.H., Hassan M.A., Mahmoud M.A. 2010: Infestation of some marine fish species with red worm Philometra. Arab Gulf J. Sci. Res. 28: 137-146.

Moнan R.S.L. 1971: On the infestation of the gonadial nematode parasite Philometra rajani Mukherjee from the sciaenid fish Pennahia aneus (Bloch) from Palk Bay. J. Mar. Biol. Ass. India 12: $226-227$

Moravec F. 2004: Some aspects of the taxonomy and biology of dracunculoid nematodes parasitic in fishes: a review. Folia Parasitologica 51: 1-13.

Moravec F. 2006: Dracunculoid and Anguillicoloid Nematodes Parasitic in Vertebrates. Academia, Prague, 634 pp.

Moravec F. 2008: Systematic status of Philometra jordanoi (López-Neyra, 1951) and some other congeneric species previously identified as Philometra lateolabracis (Yamaguti, 1935) (Nematoda: Philometridae). Folia Parasitol. 55: 159-160.

Moravec F., Bakenhaster M. 2010: Philometrid nematodes infecting fishes from the Everglades National Park, Florida, USA, with description of two new species. Folia Parasitol. 57: 213-222.

Moravec F., Bakenhaster M., de Buron I. 2013: A new gonadinfecting species of Philometra (Nematoda: Philometridae) from the Atlantic Spanish mackerel Scomberomorus maculatus (Scombridae) off the Atlantic coast of Florida and South Carolina. J. Parasitol., in press.

Moravec F., De Buron I. 2009: New data on three gonad-infecting species of Philometra (Nematoda, Philometridae) from estuarine fishes in South Carolina, USA. Acta Parasitol. 54: 244-252.

Moravec F., De Buron I. 2013: A synthesis of our current understanding of philometrids (Philometridae), a group of growingly important fish parasites. Folia Parasitol. 60: .

Moravec F., de Buron I., Baker T.G., GonzÁlez-Solís D. 2008: Some gonad-infecting species of Philometra (Nematoda, Philometridae) from offshore fishes of South Carolina and Georgia, USA, including Philometra charlestonensis sp. nov. from the scamp Mycteroperca phenax. Acta Parasitol. 53: 382-391.

Moravec F., De Buron I., Roumillat W.A. 2006: Two new species of Philometra (Nematoda: Philometridae) parasitic in the perciform fish Cynoscion nebulosus (Sciaenidae) in the estuaries of South Carolina, USA. Folia Parasitol. 53: 63-70.

Moravec F., Chávez R.A., Oliva M.E. 2011b: A new gonad-infecting species of Philometra (Nematoda: Philometridae) from the red cusk-eel Genypterus chilensis (Osteichthyes: Ophidiidae) off Chile. Parasitol. Res. 108: 227-232.

Moravec F., Fajer-Avila E.J., Bakenhaster M. 2010: Philometra floridensis sp. n. (Nematoda: Philometridae) from the ovary of red drum Sciaenops ocellatus (Osteichthyes: Sciaenidae) off the coast of Florida, USA. J. Helminthol. 84: 49-54.

Moravec F., Gopalakrishnan A., Rajkumar M., Saravanakumar A., Kaliyamoorthy S. 2011a: A new gonad-infecting species of Philometra Costa, 1845 (Nematoda: Philometridae) from the marine fish Terapon jarbua (Forsskål) (Terapontidae) off the eastern coast of India. Syst. Parasitol. 80: 23-33.

Moravec F., Jassim A.A.R., Al-SAlim N.K. 2012b: Philometroides acanthopagri sp. nov., a new philometrid (Nematoda, Philometridae) from the musculature of Acanthopagrus latus (Sparidae) from marine waters of Iraq. Acta Parasitol. 57: 372-377.

Moravec F., Justine J.-L. 2008: Some philometrid nematodes (Philometridae), including four new species of Philometra, from marine fishes off New Caledonia. Acta Parasitol. 53: 369-381.

Moravec F., Justine J.-L. 2009: New data on dracunculoid nematodes from fishes off New Caledonia, including four new species of Philometra (Philometridae) and Ichthyofilaria (Guyanemidae). Folia Parasitol. 56: 129-142

Moravec F., Justine J.-L. 2011: Two new gonad-infecting species of Philometra (Nematoda: Philometridae) from the marine fish Lutjanus vitta (Perciformes: Lutjanidae) off New Caledonia. Folia Parasitol. 58: 302-310.

Moravec F., Nagasawa K., Nohara K. 2012c: Two species of philometrid nematodes (Philometridae) from marine fishes off Japan, including Philometroides branchiostegi sp. n. from Branchiostegus japonicus (Malacanthidae). Folia Parasitol. 59: 71-78.

Moravec F., Nagasawa K., Ogawa K. 1998: Observations of five species of philometrid nematodes from marine fishes in Japan. Syst. Parasitol. 40: 67-80.

Moravec F., Prista N., Costa M.J. 2007: Meagre Argyrosomus regius (Osteichthyes) as host of a gonad-infecting species of Philometra (Nematoda: Philometridae) off the Atlantic coast of Portugal. Dis. Aquat. Org. 78: 83-86.

Moravec F., Walter T., Yuniar A.T. 2012a: Five new species of philometrid nematodes (Philometridae) from marine fishes off Java, Indonesia. Folia Parasitol. 59: 115-130.

Mukherjee R.P. 1963: On a new nematode from the ovary of Indian fishes. J. Zool. Soc. India 15: 76-78.

Parukhin A.M. 1971: [Nematodes from fishes of the Red Sea and Indian Ocean.] Vol. "Voprosy ekologii ryb yuznykh morey", Biologiya Morya 23. Naukova Dumka, Kiev, pp. 177-193. (In Russian.)

Parukhin A.M. 1976: [Parasitic Worms of Commercial Fishes of the Southern Seas.] Naukova Dumka, Kiev, 183 pp. (In Russian.)

Parukhin A.M. 1989: [Parasitic Worms of Benthic Fishes of the Southern Seas.] Naukova Dumka, Kiev, 154 pp. (In Russian.)

Petter A.J., Sey O. 1997: Nematode parasites of marine fishes from Kuwait, with a description of Cucullanus trachinoti $\mathrm{n}$. sp. from Trachinotus blochi. Zoosystema 19: 35-59.

Quiazon K.M.A, Yoshinaga T., Ogawa K. 2008a: Taxonomical study into two new species of Philometra (Nematoda: Philometridae) previously identified as Philometra lateolabracis (Yamaguti, 1935). Folia Parasitol. 55: 29-41.

Quiazon K.M.A., Yoshinaga T., Ogawa K. 2008b: Philometra sawara sp. $\mathrm{n}$. and a redescription of Philometra sciaenae Yamaguti, 1941 and Philometra nemipteri Luo, 2001 (Nema- 
toda: Philometridae): a morphological and molecular approach. Folia Parasitol. 55: 277-290.

Rajyalakshmi I., Hanumantha Rao K., Shyamasundari K. 1985: On Philometra neolateolabracis n. sp. (Philometridae Baylis and Daubney, 1926) from the ovary of marine fish, Johnius argentatus Fowler. Riv. Parassitol. 2 (46): 417-422.

Rasheed S. 1963: A revision of the genus Philometra Costa, 1845. J. Helminthol. 37: 89-130.

Rasheed S. 1965: Additional notes on the family Philometridae Baylis and Daubney, 1926. J. Helminthol. 39: 349-362.
Sood M.L. 1989: Fish Nematodes from South Asia. Kalyani Publishers, New Delhi-Ludhiana, 703 pp.

Soota T.D. 1983: Studies on nematode parasites of Indian vertebrates I. Fishes. Records of the Zoological Survey of India, occasional paper no. 54. Zoological Survey of India, Calcutta, $352 \mathrm{pp}$.

Yamaguti S. 1941: Studies on the helminth fauna of Japan. Part 33. II. Nematodes of fishes. Jpn. J. Zool. 9: 343-396. 